\title{
Investigation on life events, social support and coping style of patients with breast cancer in Wuhan city, China: a case-control study
}

\author{
Qiong Dai ${ }^{1 \#}$, Jianqiong Liu ${ }^{1 \#}$, Bei Liu², Jiangshan Cao ${ }^{1 *}$, and Yukai Du ${ }^{3 *}$ \\ ${ }^{1}$ Department of Child Health Care, Hubei Maternal and Child Health Hospital, China \\ ${ }^{2}$ Department of technical guidance, Family Planning Service Center in Jinan city, China \\ ${ }^{3}$ Department of Maternal Health Care, Department of Maternal and Children Health Care and Adolescent Hygiene, School of Public Health, Tongji Medical \\ College, Huazhong University of Science and Technology, China \\ \#Qiong Dai and Jianqiong Liu contributed equally to this work.
}

\begin{abstract}
Objective: To investigate the influential factors among life events, traits coping style and social support in breast cancer patients.

Methods: We conducted a 1:1 case-control matched study, selecting 400 female patients as case group and 400 matched healthy females as control group. Each group was given an interview respectively.

Results: Statistically significant differences were found in level of negative events, total scale, family problem, work and study problem in the life event scale (LES), $(\mathrm{p}<.0001$ respectively). Subjective support and the scale of social support in the social support rating scale (SSRS) were significantly negatively associated with breast cancer patients $(\mathrm{OR}$ (subjective support) $=0.697,95 \% \mathrm{CI} 0.576-0.844, \mathrm{p}=0.0002$; OR (the scale of social support) $=0.655,95 \% \mathrm{CI} 0.560-0.765 ; \mathrm{p}<.0001$ ). Negative coping in the traits coping style questionnaire (TCSQ) and negative events in LES were significantly positively associated with breast cancer patients (OR (negative coping $=1.149,95 \%$ CI 1.103-1.197; $\mathrm{p}<.0001 ;$ OR (negative events) $=1.051,95 \%$ CI 1.034-1.067; $<<.0001$ ).

Conclusion: Life events, traits coping style and social support may have certain relationship with breast cancer patients. Further analyses carefully addressing the bias including the effect of mood congruence are warranted to better understand the cause-effect relationship between the life events, traits coping style and social support and breast cancer incidence.
\end{abstract}

\section{Introduction}

Life events and accompanying psychological and behavioral reactions often have an impact upon people's daily lives and are believed to predispose them to disease [1]. Observational studies have established that stressful life events, often defined as an accumulation of ordinary life events or bereavement, increase the risks of mental disorders, acute infections such as the common cold, and total and cause-specific mortality. Life events have also been suggested to contribute to various other diseases, including cardiovascular diseases, cancer, asthma, and rheumatoid arthritis.

The psychological definition of coping is the process of managing taxing circumstances, expending effort to solve personal and interpersonal problems, and seeking to master, minimize, reduce or tolerate stress or conflict [2].

Social support is the physical and emotional comfort given to us by our family, friends, co-workers and others, and is often used in a broad sense, including social integration [3]. Social integration refers to the structure and quantity of social relationships, such as the size and density of networks and the frequency of interaction, but also sometimes to the subjective perception of embeddedness. Social support in the narrow sense has been defined in various ways. For example, it may be regarded as resources provided by others, as coping assistance or as an exchange of resources [4].

As modern medical model is transforming from biomedical model to biology-psychology-community medical model, there has been increasing interest in the association between psychosocial factors and breast cancer risk. Several studies have demonstrated that $30 \%-40 \%$ of cancer patients suffer from psychiatric problems such as depression, anxiety and adjustment disorders [5-7]. On the basis of these facts, this study examined the association between the influential factors among life events, traits coping style, social support in breast cancer patients and the control population.

Correspondence to: Jiangshan Cao, Department of Maternal Health Care, Hubei Maternal and Child Health Hospital, Wuhan, 430070, China; Tel: 8618986001653; E-mail: Caojs68@163.com

Yukai Du, Department of Maternal and Children Health Care and Adolescent Hygiene, School of Public Health, Tongji Medical College, Huazhong University of Science and Technology, Wuhan, 430030, China, Tel: 86-27-83692753; E-mail: duyukai2000@163.com

Key words: life events, social support, coping style, breast cancer

Received: March 16, 2017; Accepted: April 26, 2017; Published: April 28, 2017 


\section{Materials and methods}

\section{Source of case group and control group}

Case group selected 400 female breast cancer patients between the ages of 23-80 years old, diagnosed with a first, pathologically confirmed breast cancer between June 2015 and May 2016, were identified in three hospitals, including Tongji Hospital, Xiehe Hospital and Wuhan Central Hospital in Wuhan City, Hubei Province of China. Control group was 1:1 frequency-matched to the breast cancer case within 5 -year age groups and adjusted by education, occupational status, inhabited area and marital status.

\section{Data collection}

Face-to-face interviews were conducted in the in-patients settings in the three hospitals--Tongji Hospital, Xiehe Hospital and the Wuhan Central Hospital. Interviewers were trained in survey and mental assessment methods. The same interviewer interviewed both cases and the age-matched controls to reduce information bias. Information on demographic characteristics (ethnicity, residence), marital and reproductive history, weight and height, dietary and physical activity habits, medical history, and family history of breast cancer was ascertained directly from the subjects. All participants were interviewed with life event scale (LES), traits coping style questionnaire (TCSQ), and social support rating scale (SSRS), in which they were asked to recall major stressful life events and their feelings.

\section{Psychosocial measures}

Three questionnaires were administered as following:

Life event scale (LES) [7] revised by Dr. Yang De-sen was used to investigate the significant events that happened during the previous 5 years. The LES is a 48 -item measure of life changes, including the family, work and study, social and other problems, and is ranked to show the most stressful to the least stressful degrees and the impact ranging from 3 months to over a year, and is associated to physical and psychological ill health.

Social support was measured by the social support rating scale (SSRS) [7]. The SSRS, 10 items, is to assess the four levels of score, objective and subjective support, utility degree of social support, and measures perceived availability (the number of people that the individual thinks he or she can count on, if necessary) and satisfaction with perceived social support.

Coping style was measured with traits coping style questionnaire (TCSQ) [7] designed by Dr. Jiang Qian-jin and the results were presented as positive coping score (PC) and negative coping score (NC). The TCSQ composed of positive coping and negative coping, and each factor was respectively composed of 10 items, the scores on coping styles were assessed by the difference between negative coping and positive coping. The higher the scores, the more negative the coping styles were. The extent to which each item has been experienced is rated on a 5-point scale, ranging from 1 (very positive) to 5 (very negative).

\section{Data analysis}

All data was carried out with SAS 9.0 software. Descriptive statistics were calculated for all variables. All data was presented as mean \pm standard deviation (SD) and analyzed by Student $t$ tests (for continuous data) and $\chi^{2}$ tests (for categorical data) to assess differences between the case and control groups. Conditional logistic regression analysis [8] was adopted to assess the predictive relationships of life events, social support, coping style and breast cancer risk. All model Odds Ratios and
Table 1. Comparison of baseline characteristics between case group and control group

\begin{tabular}{|c|c|c|c|c|}
\hline Variable & Cases $(n=400)$ & Control(n=400) & $\chi^{2}$ values & $P$ values \\
\hline \multicolumn{5}{|c|}{ Age (years) } \\
\hline$\leq 30 \mathrm{~N}(\%)$ & $9(2.30 \%)$ & $7(1.75 \%)$ & & \\
\hline $31-40 \mathrm{~N}(\%)$ & $55(13.70 \%)$ & $55(13.75 \%)$ & & \\
\hline $41-50 \mathrm{~N}(\%)$ & $161(40.20 \%)$ & $158(39.50 \%)$ & & \\
\hline $51-60 \mathrm{~N}(\%)$ & $122(30.60 \%)$ & $128(32.00 \%)$ & & \\
\hline \multirow[t]{2}{*}{$\geq 61 \mathrm{~N}(\%)$} & $53(13.20 \%)$ & $52(13.00 \%)$ & & \\
\hline & & & 0.089 & 0.77 \\
\hline \multicolumn{5}{|c|}{ Education, N (\%) } \\
\hline$\leq 6$ years & $69(17.40 \%)$ & $74(18.50 \%)$ & & \\
\hline $7-9$ & $123(33.30 \%)$ & $121(30.30 \%)$ & & \\
\hline $10-12$ & $86(23.30 \%)$ & $99(24.70 \%)$ & & \\
\hline $13-17$ & $53(14.20 \%)$ & $60(14.90 \%)$ & & \\
\hline \multirow[t]{2}{*}{$>18$} & $38(11.10 \%)$ & $46(11.60 \%)$ & & \\
\hline & & & 0.530 & 0.47 \\
\hline \multicolumn{5}{|c|}{ Occupational status } \\
\hline Employed & $232(55.75 \%)$ & $226(56.50 \%)$ & & \\
\hline Unemployed & $64(16.00 \%)$ & $66(16.50 \%)$ & & \\
\hline \multirow[t]{2}{*}{ Retired } & $104(26.00 \%)$ & $108(27.00 \%)$ & & \\
\hline & & & 0.168 & 0.68 \\
\hline \multicolumn{5}{|c|}{ Inhabited area } \\
\hline City & $266(66.50 \%)$ & $259(64.75 \%)$ & & \\
\hline \multirow[t]{2}{*}{ Countryside } & $134(33.50 \%)$ & $141(35.25 \%)$ & & \\
\hline & & & 0.271 & 0.60 \\
\hline \multicolumn{5}{|c|}{ Marital status } \\
\hline $\begin{array}{l}\text { The first } \\
\text { marriage }\end{array}$ & $360(88.70 \%)$ & $364(91.00 \%)$ & & \\
\hline Remarriage & $5(1.40 \%)$ & $4(1.00 \%)$ & & \\
\hline $\begin{array}{l}\text { Divorced/ } \\
\text { separated }\end{array}$ & $17(4.70 \%)$ & $15(3.75 \%)$ & & \\
\hline Widowed & $14(3.80 \%)$ & $16(4.00 \%)$ & & \\
\hline \multirow[t]{2}{*}{ Single } & $4(1.00 \%)$ & $1(0.25 \%)$ & & \\
\hline & & & 0.272 & 0.60 \\
\hline
\end{tabular}

95\% Confidence Intervals were calculated. P value less than 0.05 was considered statistically significant.

\section{Results}

Baseline characteristics of women diagnosed with breast cancer and their matched controls are presented in Table 1

There was no significant differences concerning age, education, occupational status, inhabited area and marital status between the case and control groups ( $\mathrm{t}$-test, $\mathrm{P}=0.77, \mathrm{P}=0.47, \mathrm{P}=0.68, \mathrm{P}=0.60$ and $\mathrm{P}=0.60$, respectively).

Associations between each of the 12 independent variables in independent 3 questionnaires-life event scale (LES scores), traits coping style questionnaire (TCSQ scores) and social support rating scale (SSRS scores)-were examined separately at the different points of assessment as shown in Table 2.

Statistically significant differences were found in level of negative events, total scale, family problem, work and study problem in LES, ( $\mathrm{t}$-test, $\mathrm{p}<.0001$ respectively). On the other hand, no statistically significant differences were found in level of positive events and sociality and other problems in LES ( $\mathrm{t}$-test, $\mathrm{P}=0.6544$ and $\mathrm{P}=0.98$, respectively).

Table 3 shows the association of breast cancer with LES, TCSQ and SSRS by multiple conditional logistic regression model analysis. Psychosocial factors in LES, TCSQ and SSRS are as independent variables, and whether the case of breast cancer is as dependent variable (breast cancer $=1$, no breast cancer $=0$ ). 
Table 2. Comparison between case group and control group regarding the scale of LES, TCSQ, $\operatorname{SSRS}$ in $(\mathrm{X} \pm \mathrm{s})$

\begin{tabular}{|c|c|c|c|c|c|}
\hline Questionnaire & Variable & $\begin{array}{c}\text { Case } \\
(\mathbf{n}=\mathbf{4 0 0})\end{array}$ & $\begin{array}{c}\text { Control } \\
\mathbf{( n = 4 0 0 )}\end{array}$ & $\begin{array}{c}\mathbf{t} \\
\text { values }\end{array}$ & $\begin{array}{c}\mathbf{p} \\
\text { values }\end{array}$ \\
\hline & \multicolumn{5}{|c|}{ LES } \\
\hline & Positive events & $10.0 \pm 40.61$ & $11.38 \pm 42.60$ & 0.45 & 0.6544 \\
\hline & Negative events & $78.0 \pm 66.92$ & $4.01 \pm 19.77$ & 21.07 & $<.0001$ \\
\hline & Total scale & $88.0 \pm 75.65$ & $15.39 \pm 48.71$ & 16.01 & $<.0001$ \\
\hline & Family problem & $72.6 \pm 63.71$ & $5.40 \pm 18.64$ & 20.25 & $<.0001$ \\
\hline & Work and study problem & $7.66 \pm 22.20$ & $1.42 \pm 6.52$ & 5.35 & $<.0001$ \\
\hline & $\begin{array}{c}\text { Sociality and other } \\
\text { problems }\end{array}$ & $0.21 \pm 2.84$ & $0.21 \pm 1.79$ & 0.03 & 0.98 \\
\hline & TCSQ & & \\
\hline & Positive coping & $23.50 \pm 9.85$ & $38.07 \pm 6.31$ & 24.94 & $<.0001$ \\
\hline & Negative coping & $36.99 \pm 9.26$ & $19.47 \pm 5.99$ & 30.92 & $<.0001$ \\
\hline & SSRS & & \\
\hline & Scale & $24.15 \pm 7.28$ & $38.31 \pm 7.05$ & 28.16 & $<.0001$ \\
\hline & Objective support & $5.29 \pm 2.47$ & $9.35 \pm 2.71$ & 21.71 & $<.0001$ \\
\hline & Subjective support & $14.70 \pm 4.35$ & $21.50 \pm 4.17$ & 23.28 & $<.0001$ \\
\hline & Utility degree of social \\
& support & $4.20 \pm 1.98$ & $7.49 \pm 1.87$ & 24.19 & $<.0001$ \\
\hline &
\end{tabular}

Table 3. Factors in LES, TCSQ and SSRS significantly associated with breast cancer

\begin{tabular}{|c|c|c|c|c|}
\hline Factor & OR & $\mathbf{9 5 \% C I}$ & $\boldsymbol{\chi}^{\mathbf{2}}$ & P \\
\hline Negativecoping & 1.149 & $1.103-1.197$ & 44.7080 & $<.0001$ \\
\hline Subjectivesupport & 0.697 & $0.576-0.844$ & 13.7143 & 0.0002 \\
\hline The scale of social support & 0.655 & $0.560-0.765$ & 28.2447 & $<.0001$ \\
\hline Negative events & 1.051 & $1.034-1.067$ & 38.3910 & $<.0001$ \\
\hline
\end{tabular}

Subjective support and the scale in SSRS were significantly negatively associated with breast cancer patients (OR (subjective support) $=0.697$, 95\%CI 0.576-0.844, $\mathrm{P}=0.0002$; OR (the scale of social support) $=0.655$, 95\%CI $0.560-0.765 ; \mathrm{P}<.0001)$. Negative coping in TCSQ and negative events in LES were significantly positively associated with breast cancer patients (OR (negative coping) $=1.149,95 \%$ CI 1.103-1.197, $\mathrm{p}<.0001$; OR [negative events] $=1.051,95 \% \mathrm{CI} 1.034-1.067 ; \mathrm{P}<.0001)$.

\section{Discussion}

\section{Life events}

The result of this study showed that the scale of negative life events was associated with the risk factors for breast cancer (OR: 1.051; 95\%CI: 1.034-1.067). The life event scale results showed that both case and control group in the scale of negative life events and the total scale of life events were statistically significant $(\mathrm{P}<.0001)$, while the scale of positive events was not statistically significant $(P=0.6544)$. As to the types of life events, the scale of family problems, work and study problem were statistically significant between the case and control group $(\mathrm{P}<.0001)$, while the scale of social and other issues were not statistically significance $(\mathrm{P}=0.98)$. We presume that the negative life events have more psychological impact on patients than positive ones. And greater impact comes from family problems and personal work and study problems rather than from social and other problems. This suggests the importance of family life to women. At the same time, the increasingly fierce competition in society has brought greater pressure to women from work and study.

Previous analyses (Price, 2001; Kirsi, 2003; Dai, 2006) has also indicated an association between breast cancer risk and life events [911]. In short, women who have been exposed to a number of negative life events are considered risk factors for breast cancer. Evidence linking social support to health has indicated the involvement of specific physiological mechanisms. The mechanism in which the central nervous, hormonal and immune systems interact with one another and how behaviors and external events modulate these three systems is not fully understood, however, we think that traumatic or stressful events have long-lasting effects on stress-response systems, such as the hypothalamic-pituitary-adrenal (HPA) axis. Prolonged exposure to stress leads to HPA-mediated endocrine activation and increased production of cortisol, which diverts biological systems from normal functions to the threat posed by stress. Extended periods of stress and trauma and its resulting cortisol production may interfere with the body's ability to fight with cancer progression. When there is consistent, long-term stress in the body, the elevated cortisol level may change the body's normal rhythms and potentially reduce resistance to tumor growth [12]. We can come to the conclusion that experiencing more than one meaningful life event (severe and/or mild to moderate) is a risk factor for breast cancer.

\section{Trait coping style}

To be human is to experience crisis. The reaction to the same crisis differs from one to the other. The emotional experience is as individual as the other characteristics of the person. The result of this study showed that negative coping with higher scale was associated with the risk factors for breast cancer (OR: 1.149; 95\%CI: 1.103-1.197). The traits coping style questionnaire (TCSQ) results showed that both case and control group in the scale of negative coping and positive coping were statistically significant $(\mathrm{P}<.0001)$. We presume, therefore, that negative coping to face the stress would be detrimental to the physical and mental health while positive coping is beneficial. Due to the lack of capacity to negative emotional catharsis, the tensions linked to the strongest emotion convey and derail in the body. The accumulation of repressed negative energy can cause symptoms and psychosomatic diseases.

In coping with different life events, especially negative life events, the person with lower scale in negative coping modifies the way they think, for example: employing denial, or distancing oneself from the problem. People may alter the way they think about a problem by altering their goals and values, such as by seeing the humour in a situation, while the person with higher scale in negative coping is opposite. In the case group, higher score in negative coping and lower score in positive coping can undoubtedly be explained by breast cancer and the emotional disruption that this event brings. The result, in fact, showed that individuals in case group, meeting negative events, often give up to their emotions, to vent, cry, and surrender rather than positive coping such as solving embarrassed situation by humor. Previous studies have also indicated an association between breast cancer risk and traits coping style [13-16]. Positive coping can mobilize sufficiently the internal vitality of the body for the patients to adapt well so that the negative emotion, such as helplessness, depression can be lower. Suppression of negative emotions induced by a stressor might be associated with immunological changes, which, in turn, speed up the evolution of the disease [17].

There is some evidence that such programs influence immune processes [18-21], although more research is needed to establish whether these effects reduce recurrence or increase survival [22-23]. What's more, G. Manna, et al. (2007) [24] reported that the subjects affected with mammary carcinoma have a reduced capacity to control their emotions and tend to use rigid reaction mechanisms to stress (negation or repression) and to interject aggression. Weihs, et al. (2000) [25] also found that restriction of emotion predicted higher mortality in recurrent breast cancer. In short, the adaptation to particularly stressful situations is the flexibility in the use of coping strategies to release negative emotion. These findings raise the possibility that 
emotional health can reduce a woman's risk of developing breast cancer. At the same time, general feelings of happiness and optimism can play a protective role against the disease. Thus, the relationship between happiness and health should be examined in the future studies and the relevant preventative initiatives should be developed.

\section{Social support}

The result of this study showed that subjective support and total social support with higher scale were associated with a decreased risk of breast cancer (subjective support: OR: 0.697; 95\%CI: 0.576-0.844; the scale of social support: OR: $0.655 ; 95 \% \mathrm{CI}: 0.560-0.765$ ). The social support rating scale (SSRS scores) results showed that both case and control group in the scale of social support, objective support, subjective support and utility degree of social support were statistically significant $(\mathrm{P}<.0001)$. Thus, we think that the availability of support (family, friends, relatives) was significantly related to reduce risk of breast cancer.

Comparing with case group, individuals who have to face difficulties in control group not only has good objective support, such as: to get help in material resource and spiritual care from spouse, family, friends, and so on. At the same time, they have better subjective support and utility degree of social support--- sense the subjective concern from family, friends, colleagues and neighbors. What's more, they can better use coping strategies such as the reduction of negative affects (state-anxiety) and self-reassurance such as awareness of the availability of social support. In fact, previous studies have also indicated an association between breast cancer risk and social support [26]. In addition, JULIE M, et al. (2000) [27] reported that greater quality of social support is associated with lower cortisol concentrations in women with metastatic breast cancer, which is indicative of healthier neuroendocrine functioning. Candyce $\mathrm{H}$, et al. (2006) [28] reported that socially isolated women had an elevated risk of mortality after a diagnosis of breast cancer due to a lack of access to care, specifically beneficial caregiving from spouse, friends, relatives, and adult children. Even as Cohen $S$ reported that naturally-occurring networks may be more critical to health [29].

To sum up, life events, trait coping style and social support may have certain relationship with breast cancer patients. For the prevention of female breast cancer, it is essential to decrease negative life events, reduce the negative emotional response and increase social support against negative life events. What's more, case-control studies are notoriously susceptible to bias. We have tried to reduce sampling bias by recruiting from three hospitals serving a defined catchment area, and by making an initial contact with participants in the breast surgical ward so that losses and refusals were reduced to a minimum. To reduce reporting and measurement bias, we used two interviewers and ensured that borderline events and difficulties were rated at consensus meetings, and that equivocal stressors were rated by a third person unaware of the diagnosis. Apart from this, we avoided subgroup reanalysis, restricting our study to the association between onset of breast cancer and the experience of four types of stressor, which were specified before data were collected. However, like all case-control studies, it has potential limitations. For example, the results could have been affected by recollection bias because participants were asked to recall past feelings and events.

\section{Authorship and contributorship}

All the authors listed meet the under conditions: 1) substantial contributions to conception and design, or acquisition of data, or analysis and interpretation of data; 2) drafting the article or revising it critically for important intellectual content; 3) final approval of the version to be published; 4) agreement to act as guarantor of the work. Qiong Dai and Jianqiong Liu contributed equally to this work.

\section{Acknowledgments}

Special thanks go to all the patients who participated in the study. This work was supported by grants from Tongji Hospital, Xiehe Hospital and the Wuhan Central Hospital, and it is done with the help of Associate Professor Wang Ping in revising the manuscript.

\section{Competing interests}

The authors declare that there are no conflicts of interests (political, personal, religious, ideological, academic, intellectual, commercial or any other) in relation to this manuscript.

\section{References}

1. Yu HL, Li Y, Mao XQ, Ma R, Sun JZ, et al. (2007) Physiological and psychological improvements of Chinese women with breast cancer in perioperative period after brief structured psychotherapy. Chin Med J 120:74-76. [Crossref]

2. Gil S, Caspi Y(2006) Personality traits, coping Style, and perceived threat as predictors of posttraumatic stress disorder after exposure to a terrorist attack: a prospective study. Psycho Med 68:904-909. [Crossref]

3. Friedman LC1, Kalidas M, Elledge R, Chang J, Romero C, et al. (2006) Optimism, social support and psychosocial functioning among women with breast cancer. Psychooncology 15: 595-603. [Crossref]

4. Hosaka T, Sugiyama Y, Hirai K, Okuyama T, Sugawara Y, et al. (2001) Effects of a modified group intervention with early-stage breast cancer patients.Gen Hosp Psychiatry 23: 145-151. [Crossref]

5. Okamura M, Yamawaki S, Akechi T, Taniguchi K, Uchitomi Y (2005) Psychiatric disorders following first breast cancer recurrence: prevalence, associated factors and relationship to quality of life. J Clin Oncol 35: 302-309. [Crossref]

6. Wong-Kim EC1, Bloom JR (2005) Depression experienced by young women newly diagnosed with breast cancer. Psychooncology 14: 564-573. [Crossref]

7. Wang X, Xilin, Ma H (1999) Life event scale. Psychological Hygiene Assessment Scale Manual (updated version). Beijin: Chinese Psychological Hygiene Journal Publishing House.

8. Smith PG, Smith MC, Pike AP, Hill NE, Breslow NE (1981) Algorithm AS 162 Multivariate Conditional Logistic Analysis of Stratum- Matched Case-Control Studies. J Royal Statistical Society. Series C (Applied Statistics) 30: 190-197

9. Price MA, Tennant CC, Butow PN, Smith RC, Kennedy SJ, et al. (2001) The role of psychosocial factors in the development of breast carcinoma: Part II. Life event stressors, social support, defense style, and emotional control and their interactions. Cancer 91: 686-697. [Crossref]

10. Lillberg K, Verkasalo PK, Kaprio1 J, Teppo L, Helenius H, et al. (2003) Stressful Life Events and Risk of Breast Cancer in 10,808 Women: A Cohort Study. Am J Epidemiol 157:415-423. [Crossref]

11. Qiong D, Yukai D (2006) Investigation on the Life Events of the Female Patients with Breast Cancer in Wuhan City. Medicine and Society 19:16-18.

12. Kirschbaum C, Hellhammer DH (1994) Salivary cortisol in psycho neuroendocrine research: recent developments and applications. Psychoneuroendocrinology 19: 313333. [Crossref]

13. Jensen KP, Bäck-Pettersson S, Segesten K (2000) The meaning of "not giving in" Lived experiences among women with breast cancer. Cancer Nurs 23: 6-11. [Crossref]

14. Kornblith AB, Herndon JE 2nd, Zuckerman E, Viscoli CM, Horwitz RI, et al. (2001) Social support as a buffer to the psychological impact of stressful life events in women with breast cancer. Cancer 91: 443-454. [Crossref]

15. Butow PN, Coates AS, Dunn SM (2000) Psychosocial predictors of survival: metastatic breast cancer. Ann Oncol 11: 469-474. [Crossref]

16. Cousson-Ge 'lie F (2000) Breast cancer, coping, and quality of life: a semi-prospective study. Eur Rev Appl Psychol 50:315-320.

17. Cousson-gelie F, Bruchon-schweitzar M, Dilhuydy JM, et al. (2007) Do anxiety,body image, social support and coping strategies predict survival in breast cancer? A ten-year follow-up study. Psychosomatics 48:3. 
18. Fawzy FI, Kemeny MF, Fawzy NW, Elashoff R, Morton D, et al. (1990) A structured psychiatric intervention for cancer patients: II. changes over time in immunological measures. Arch Gen Psychiatry 47:729-735. [Crossref]

19. McGregor BA, Antoni MH, Boyers A, Alferi SM, Blomberg BB, et al. (2004) Cognitive-behavioral stress management increases benefit finding and immune function among women with early-stage breast cancer. J Psychosom Res 56: 1-8. [Crossref]

20. Carlson LE, Speca M, Patel K, Goodey E (2003) Mindfulness based stress reduction in relation to quality of life, mood, symptoms of stress and immune parameters in breast and prostate cancer outpatients. Psychosom Med 65:571-581.[Crossref]

21. Andersen BL, Farrar WB, Golden-Kreutz DM, Glaser R, Emery CF, et al. (2004) Psychological, behavioral, and immune changes after a psychological intervention: a clinical trial. J Clin Oncol 22: 3570-3580. [Crossref]

22. Luecken LJ, Compas BE (2002) Stress, coping, and immune function in breast cancer. Ann Behav Med 24: 336-344. [Crossref]

23. Cameron LD, Booth RJ, Schlatter M, Ziginskas D, Harman JE, et al. (2005) Cognitive and Affective Determinants of Decisions to Attend a Group Psychosocial Support Program for Women with Breast Cancer. Psychosom 67:584-589. [Crossref]
24. Manna G, Foddai E, Di Maggio MG, Pace F, Colucci G, et al. (2007) Emotional expression and coping style in female breast cancer. Ann Oncol18 Suppl 6: vi77-80. [Crossref]

25. Weihs KL, Enright TM, Simmens SJ, Reiss D (2000) Negative affectivity, restriction of emotions, and site of metastases predict mortality in recurrent breast cancer. $J$ Psychosom Res 49:59-68. [Crossref]

26. Kroenke CH, Kubzansky LD, Schernhammer ES, Holmes MD, Kawachi I (2006) Social networks, social support, and survival after breast cancer diagnosis. J Clin Oncol 24: 1105-1111. [Crossref]

27. Turner-Cobb JM, Sephton SE, Koopman C, Blake-Mortimer J, Spiegel D (2000) Social support and salivary cortisol in women with metastatic breast cancer. Psychosom Med 62: 337-345. [Crossref]

28. Kroenke CH, Kubzansky LD, Schernhammer ES, Holmes MD, Kawachi I(2006) Social networks, social support, and survival after breast cancer diagnosis. J Clin Oncol 24: 1105-1111. [Crossref]

29. Cohen S (2004) Social relationships and health. Am Psychol59: 676-684. [Crossref]

Copyright: $\odot 2017$ Dai Q. This is an open-access article distributed under the terms of the Creative Commons Attribution License, which permits unrestricted use, distribution, and reproduction in any medium, provided the original author and source are credited. 